\title{
REVISIÓN Y ANÁLISIS CRÍTICO SOBRE LA IMPLEMENTACIÓN DE LA TELEVISIÓN DIGITAL TERRESTRE EN BOLIVIA
}

\section{Gustavo Siles y Andrés Laguna}

\section{RESUMEN}

El presente artículo se centra en revisar la situación de la implementación de la TDT en Bolivia, previa al Apagón Analógico, cuya postergación ha sido recientemente anunciada. Desde una perspectiva interdisciplinar, se realizó un análisis crítico de algunos aspectos, centrados en el caso boliviano, como: los criterios para la adopción del estándar ISDB-Tb, la interactividad, la multiprogramación y el modelos de negocio, los decodificadores, las tecnologías alternativas de acceso a televisión, y las políticas de gobierno. Concluimos planteando una serie de preguntas que aportan al debate sobre este nuevo sistema en Bolivia, y dejando en claro que se requieren otras miradas, no sólo una meramente técnica centrada en las mejoras que puede proponer una nueva tecnología, sino otras que ofrezcan respuestas al sector audiovisual y, en general, a la población ante este nuevo reto.

Palabras Clave: Televisión Digital, TDT, Regulación de espectro, ISDB-Tb

DOI: 10.23881/idupbo.019.1-8i 